\title{
Seasonal Variation of Algae Types, Counts and Their Effect on Purified Water Quality Case Study: Al-Mogran and Burri Plants, Khartoum State, Sudan
}

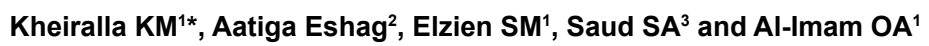 \\ ${ }^{1}$ Department of Geology, Faculty of Petroleum \& Minerals, Al Neelain University, Sudan \\ ${ }^{2}$ Khartoum State Water Corporation (KSWC), Sudan \\ ${ }^{3}$ Faculty of Nursing and Health, Khartoum University, Sudan
}

\begin{abstract}
The aim of this paper was to study the seasonal variations of algae types, counts and their effects on the quality of purified water in Al-Mogran and Burri plants in Khartoum State, Sudan, during the year 2011. In the last few years the increase of algae bloom in the Nile made big complaints from consumers and researchers in addition to their effects on the steps of water purification at Al-Mogran and Burri plants. The research methodologies consisted mainly of laboratory analysis. All the laboratory works were conducted at the central laboratories of Khartoum State Water Corporation (KSWC). Around 197 and 193 water samples were taken from the purified water at Al-Mogran and Burri plants respectively. Algae type, counts and species identification in addition to the physiochemical parameters $(\mathrm{pH}$, Total Alkalinity, Turbidity) were conducted according to the Standard Methods of Examination of Water and Waste Water. The results of algae types, counts of the samples collected from both plants (Al-Mogran and Burri) showed seasonal variations. At Al-Mogran plant the green algae were dominating in the summer and autumn seasons, while the blue green registered the highest count in winter season and diatoms appear mostly in autumn. At Burri plant the green algae and blue green were registered the highest count in summer season and the winter season for the diatoms. The green algae also showed high count in rainy season comparing with other types. With respect to physiological parameters results, the highest turbidity value was noticed in autumn, $\mathrm{pH}$ and $\mathrm{T}$. Alkalinity in summer for both plants. The study concluded that there was a seasonal variation of algae types, counts and that mostly depending on the $\mathrm{pH}$ value, clarity of water, sun light transmission, amount of nutrients and the nature of water. Also the algae distribution patterns were remained similar since 1970 but the quantity of algae increased.
\end{abstract}

Keywords: Seasonal variation; Diatoms; Al-Mogran and Burri; Algae types; Purified water

\section{Introduction}

Water is the common name applied to the liquid form of the hydrogen and oxygen compound $\mathrm{H}_{2} \mathrm{O}$. Pure water is an odorless, tasteless, clear liquid.

Without freshwater of adequate quantity and quality sustainable development will not be possible. Water pollution threatens development projects and makes water treatment essential in order to produce safe drinking water. Contamination of water bodies with substances that promote algal growth (possibly leading to eutrophication) are some of today's major causes of water quality degradation.

\section{Statement of the problem}

The phenomena of algae bloom on the River Nile and its tributaries became common in the last three years. Increased algae bloom caused bad effects in treatment plants which have not been constructed to receive high number of algae. These organisms can cause serious problems in treatment plant basins by the accumulation of growths on the walls, frequently clogging of filters, affecting the treatment processes and increase the dose of coagulant and chlorination. Clogging of the filters that mean more back wash high electricity consumption and reduced water supply level to consumers. It also affects the quality of purified water by increasing alkalinity and $\mathrm{pH}$ and slightly increased water turbidity. In addition the consumers complain from bad smell and odor starting from grassy, spicy, musty, and fishy to septic water.

\section{Objectives}

The overall objective of this work is to study the seasonal variations of algae types and counts and their effect on the quality of purified water at Al-Mogran and Burri Water Treatment Plant (WTPs). While the specific objectives are to:

- Classification, counting and identification of the various types of algae in purified water during the year 2011.

- Determination of the effects of algae on the physiochemical characteristics of purified water.

\section{Methodology}

The samples were taking from purified water in Al-Mogran and Burri Water Treatment Plants (WTP), around 179 and 193 samples respectively.

$\mathrm{PH}$, turbidity, total alkalinity were measured according to the standard methods for the examination of water and wastewater [1]. On the other hand the Odor was measured by estimation (Table 1).

*Corresponding author: Kheiralla KM, Department of Geology, Faculty of Petroleum \& Minerals, Al Neelain University, Sudan, Tel: 0024912149164; E-mail: khalidkheiralla@gmail.com

Received January 20, 2014; Accepted March 14, 2014; Published March 21, 2014

Citation: Kheiralla KM, Eshag A, Elzien SM, Saud SA, AI-Imam OA (2014) Seasonal Variation of Algae Types, Counts and their Effect on Purified Water Quality Case study: Al-Mogran and Burri Plants, Khartoum State, Sudan. J Biodivers Endanger Species 2: 122. doi:10.4172/23322543.1000122

Copyright: ( 2014 Kheiralla KM, et al. This is an open-access article distributed under the terms of the Creative Commons Attribution License, which permits unrestricted use, distribution, and reproduction in any medium, provided the original author and source are credited. 
Citation: Kheiralla KM, Eshag A, Elzien SM, Saud SA, Al-Imam OA (2014) Seasonal Variation of Algae Types, Counts and their Effect on Purified Water Quality Case study: Al-Mogran and Burri Plants, Khartoum State, Sudan. J Biodivers Endanger Species 2: 122. doi:10.4172/23322543.1000122

Page 2 of 4

\begin{tabular}{|l|c|c|c|c|c|c|}
\hline \multirow{2}{*}{ Month } & \multicolumn{3}{|c|}{ Mogran plant } & \multicolumn{3}{c|}{ Burri plant } \\
\cline { 2 - 8 } & Turbidity & pH & Total Alkalinity & Turbidity & pH & Total Alkalinity \\
\hline January & 11.6 & 7.7 & 62 & 3.1 & 7.99 & 114 \\
\hline February & 16.5 & 7.2 & 76 & 2.2 & 7.9 & 116 \\
\hline March & 9.4 & 8.2 & 104 & 2.9 & 8.12 & 120 \\
\hline April & 11.3 & 7.28 & 68 & 3.6 & 8.2 & 130 \\
\hline May & 3.1 & 8.6 & 130 & 2.7 & 8.4 & 124 \\
\hline June & 8.4 & 8.2 & 94 & 1.9 & 8.3 & 94 \\
\hline July & 8.7 & 8.2 & 0 & 8.5 & 8 & 96 \\
\hline August & 9.3 & 7.6 & 88 & 31.7 & 7.7 & 96 \\
\hline September & 9.6 & 7.6 & 82 & 8.4 & 7.8 & 82 \\
\hline October & 35.4 & 7.7 & 80 & 12.2 & 7.7 & 80 \\
\hline November & 11.7 & 7.8 & 88 & 13.5 & 7.5 & 88 \\
\hline December & 14 & 7.3 & 82 & 6.1 & 7.9 & 100 \\
\hline
\end{tabular}

Table 1: Monthly measurements of $\mathrm{pH}$, turbidity and total alkalinity in Al-Mogran and Burri WTPs.

To count algae on water samples by using the microscope and centrifuge, Lackey Drop Micro transect Counting Method was used [1], by using the following formula:

$$
\begin{aligned}
& \text { No. } / m l_{A \times S \times V}^{C \times T A}{ }_{\text {Where: }} \\
& \text { TA= area of the cover slip, } \mathrm{mm}^{2} \\
& \mathrm{~A}=\text { area of one strip } \mathrm{mm}^{2} \\
& \mathrm{C}=\text { number of organisms counted } \\
& \mathrm{S}=\text { number of strips counted } \\
& \mathrm{V}=\text { volume of sample under the cover slip (Table 2). }
\end{aligned}
$$

\section{Results}

\section{Al-mogran WTP}

Summer season: The count of green algae registered the highest number and that agrees with Sinada et al. [2], which causes odor and taste in purified water. The high count of green algae in this season might refer to clarity of water (low turbidity) that transmit the light and the suitable temperature of the summer. Also the green algae prefer the minimal nutrients that agree with Nour Aldeen et al. [3]. Some kind of green algae can develop in summer period (high temperature) with high $\mathrm{pH}$ value close to that reported by Sinada et al. [2]. The alkalinity was reached the high values and so the $\mathrm{pH}$ that agree with NourAldeen et al. [3]. In this period the station takes their water from White Nile that agree with Sinada et al. [2] and less than half count for blue green and diatoms.

Autumn season: The count of green algae also reached high number but less than summer with low count for blue green algae. It was noticed that the rainy season was the best period for diatoms to grow compared to the winter season. High growth of diatoms may refer to the ability of diatoms to grow in different strength of sun light In addition the velocity of the flow affect the algae growth [4]. Also its growth increased with silica content because it use silica in their growth $[2,4]$ and flow velocity accelerate the dispersion of diatoms [5].

Winter season: In this season it was observed that the blue green algae were reached highest count number and the anabaena species were found in most samples. High count of anabaena is due to low temperature and the $\mathrm{pH}$ reached 7.6 [2] which cause bad odor and taste in purified water. In this season the Nile comes with oxidizable

organic matter that make good medium for algae growth. In addition in this period the plant pumped the water from White Nile which is associated with high concentration of calcium and sodium, which affect the development of cyanobacteria, with proximity half count for green algae (Figure 1).

\section{Burri WTP}

Summer season: In this season the blue green algae reached highest count which causes odor and taste (low turbidity) and the reading of alkalinity and $\mathrm{pH}$ value registered their highest with reduction in green algae (highly comparing with same type in Almogran station) due to feeding from Blue Nile [2] and the low count of diatoms might refer to low nutrient. The summer season registered the biggest number of algae comparing with other seasons that also agree with Sinada et al. [2] (1972) (Figures 2-4).

Autuman season: Through the rainy season the amount of turbidity reached high value with reduction in $\mathrm{pH}$ and alkalinity values, in spite of that the count of green algae was registered the high number with low count for blue green algae and it was observed the diatoms proximity reduction to half. As general, low growth of algae comparing with the other season that despite the presence of high or moderately high of nutrient level and the velocity might be high [2].

Winter season: During this season the blue green algae were reached their highest number but less than summer with proximity half count for green algae and diatoms (Plates 1-3).

\begin{tabular}{|l|c|c|c|c|c|c|}
\hline \multirow{2}{*}{ Month } & \multicolumn{3}{|c|}{ Mogran plant } & \multicolumn{3}{c|}{ Burri plant } \\
\cline { 2 - 7 } & Green & Blue Green & Diatoms & Green & Blue Green & Diatoms \\
\hline January & 14 & 24 & 8 & 35 & 6 & 33 \\
\hline February & 191 & 9 & 46 & 246 & 98 & 109 \\
\hline March & 622 & 16 & 104 & 487 & 157 & 285 \\
\hline April & 178 & 149 & 81 & 383 & 1309 & 195 \\
\hline May & 99 & 89 & 77 & 341 & 1452 & 89 \\
\hline June & 688 & 39 & 330 & 667 & 68 & 195 \\
\hline July & 8 & 18 & 129 & 8 & 5 & 25 \\
\hline August & 4 & 14 & 58 & 3 & 11 & 89 \\
\hline September & 0 & 9 & 62 & 0 & 1 & 36 \\
\hline October & 8 & 23 & 77 & 64 & 9 & 65 \\
\hline November & 65 & 191 & 96 & 46 & 206 & 164 \\
\hline December & 55 & 450 & 73 & 424 & 1110 & 410 \\
\hline
\end{tabular}

Table 2: Count Algae on water samples using the microscope and centrifuge.

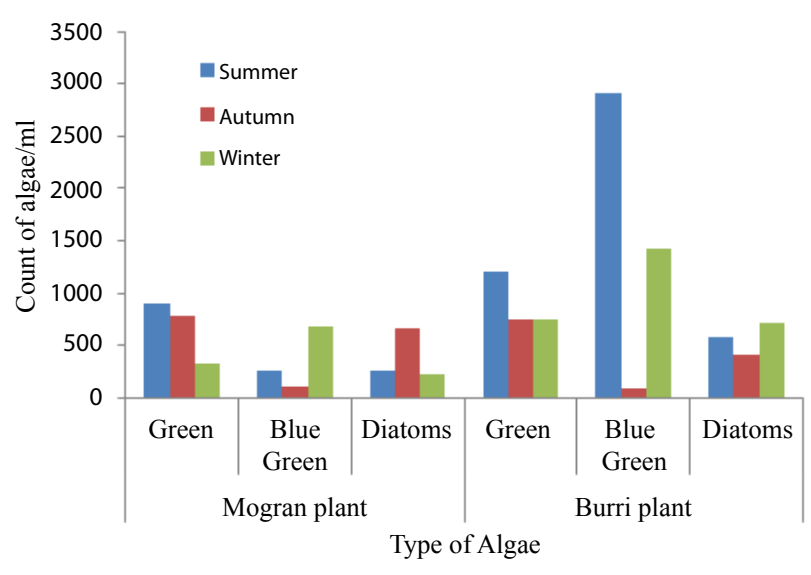

Figure 1: Seasonal counts of algae types at Al-Mogran and Burri WTPs. 
Citation: Kheiralla KM, Eshag A, Elzien SM, Saud SA, Al-Imam OA (2014) Seasonal Variation of Algae Types, Counts and their Effect on Purified Water Quality Case study: Al-Mogran and Burri Plants, Khartoum State, Sudan. J Biodivers Endanger Species 2: 122. doi:10.4172/23322543.1000122

Page 3 of 4

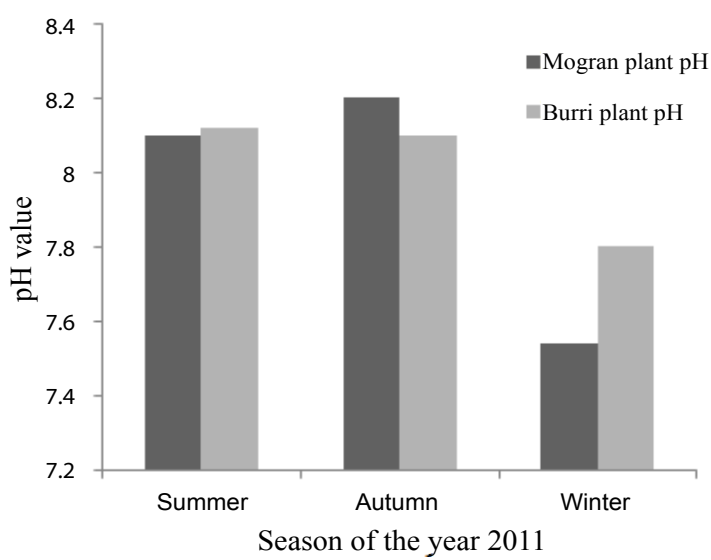

Figure 2: Seasonal variations of $\mathrm{pH}$ values at Al-Mogran and Burri WTPs.

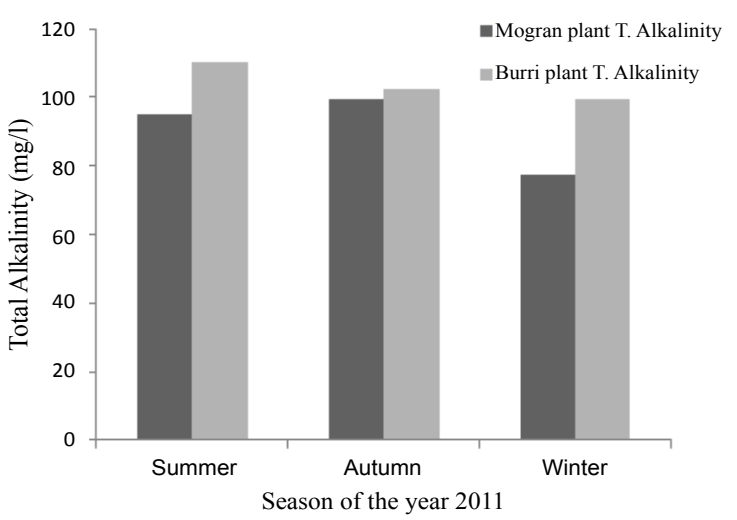

Figure 3: Seasonal variations of Total Alkalinity at Al-Mogran and Burri WTPs.

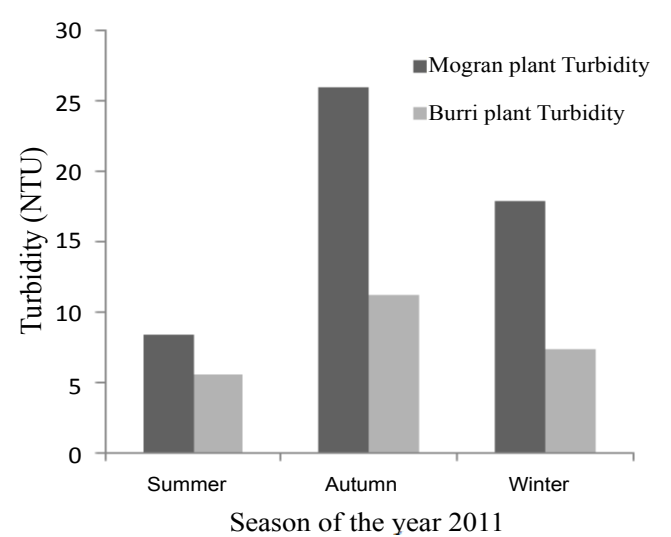

Figure 4: Seasonal variations of Turbidity at Al-Mogran and Burri WTPs.

\section{Conclusions}

- High algae counts consisted of three main groups: (green, blue green and Diatoms) and many species were identified and registered in treated water for both plants (Al-Mogran and Burri) in the three seasons, summer, winter and autumn for the year 2011.

- At Al-mogran plant the green algae registered the highest number in summer season $(749 \mathrm{count} / \mathrm{ml})$ compared to other seasons.
Diatoms registered the highest number in autumn $(644$ count $/ \mathrm{ml})$ and the blue green in winter (561 count $/ \mathrm{ml})$. Beside that the $\mathrm{pH}$ and alkalinity reach their maximum in summer then autumn and finally the winter $(8.4,7.9,7.55-117,87,75 \mathrm{mg} / \mathrm{l}$ respectively). That means there is no obvious effect for blue green algae in both $\mathrm{pH}$ and alkalinity. The turbidity shows no affect, except in rainy season which causes over load in purification processes.

- At Burri plant the blue green algae and the green algae dominated the summer season (2432 and 1009 count/ml respectively), the diatoms registered highest number in winter (596 count $/ \mathrm{ml}$ ). For chemical parameters the alkalinity reaches their highest in summer then winter and final autumn $(125,102,87 \mathrm{mg} / \mathrm{l})$. For $\mathrm{pH}$ the highest value in summer, autumn and then winter $(8.3,8.0$, 7.7). All the turbidity values in summer, autumn and winter for both plants were exceeded the permissible limits recommended by WHO Guideline values and the Sudanese standard value (7.2, 21.9, 14.05 NTU for Al-Mogran WTP and 2.8, 16.3 M 7.9 NTU for Burri WTP).

- In general, high algae count in purified water affect the
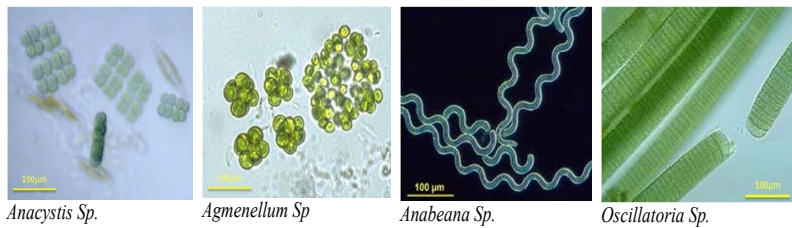

Plate 1: Shows the types of blue green algae in purified water.

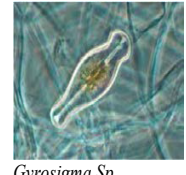

Gyrosigma Sp.

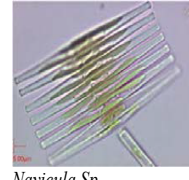

Navicula Sp.

Plate 2: Shows the types of Diatoms in purified water.

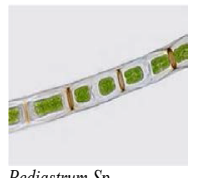

Pediastrum Sp.

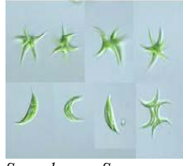

Scenedesmus $S p$

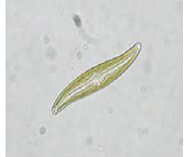

Gomphonema Sp.

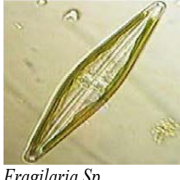

Fragilaria Sp.

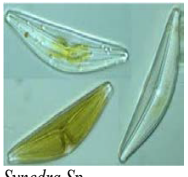

Synedra Sp.

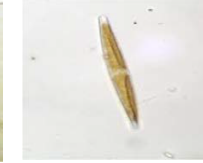

Nitszchia Sp.

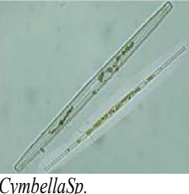

CymbellaSp.

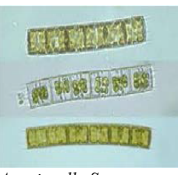

sterionella $\mathrm{Sp}$.
Plate 3: Shows the types of green algae in purified water. 
Citation: Kheiralla KM, Eshag A, Elzien SM, Saud SA, Al-Imam OA (2014) Seasonal Variation of Algae Types, Counts and their Effect on Purified Water Quality Case study: Al-Mogran and Burri Plants, Khartoum State, Sudan. J Biodivers Endanger Species 2: 122. doi:10.4172/23322543.1000122

physicochemical quality of drinking-water, which in turn affecting the consumer's health and acceptability.

- The seasonal variations of algae types, counts are mostly depending on the $\mathrm{pH}$ value, clarity of water, sun light transmission, amount of nutrients and the nature of water.

- In this study the seasonal variations pattern of algae types, counts are remained similar since 1970 , but generally the quantity increased.

\section{References}

1. Lenore S Clesceri (1998) Standard Methods for the Examination of Water and Wastewater; 20th Edn, American Public Health Association, Washington, DC, USA.
2. Sinada Faisal AbdAlla (1972) Ecology and productivity studies on the phytoplankton on the blue and white Nile at Khartoum. M.Sc. Khartoum University.

3. Nour Eldeen EE, Zayed MA, Rabie KAA, Moattassem ME (1995) The seasonal variation of the Nile water quality. J Environ Sci Heal A 30: 1957-1972.

4. Kassim IT (2007) The phytoplankton in Iraqi aquatic habitats : Ministry of Science and Technology, Directorate of Water Treatment Technology, Water Research Centre, M.Box 670 Baghdad, Iraq-Arabic copy.

5. Lefta SK, Salman JM, Jwad HJ (2010) Limnology study for Alabasia River Iraq Alkofa and Karbla University, faculty of science. 